\title{
Lipocalin-2 (Lcn2) expression is mediated by maternal nutrition during the development of the fetal liver
}

\author{
William D. Rees $\cdot$ Susan M. Hay
}

Received: 5 August 2013/ Accepted: 7 December 2013/Published online: 3 January 2014

(C) Springer-Verlag Berlin Heidelberg 2013

\begin{abstract}
The mechanisms by which maternal protein deficiency programs insulin action in the offspring are poorly understood. The interpretation of transcriptomics is complicated by homeostatic adaptations, for example, changes in amino acid metabolism, which are potentially unrelated to the programming mechanism. The fatty acid composition of the maternal diet modulates the programming of insulin action, offering a possible strategy to circumvent these complications. Fetal livers harvested on d 21 of gestation from pregnant rats fed high-protein $(18 \%$ $\mathrm{w} / \mathrm{w})$ and low-protein $(9 \% \mathrm{w} / \mathrm{w})$ diets prepared with either corn or soya oil were screened with rat genome microarrays. Although a low-protein maternal diet altered the abundance of more than one hundred mRNAs in the fetal liver, only 40 were changed by the fatty acid composition of the diet $(P<0.05)$. One of these mRNAs was identified as lipocalin-2 (Lcn2). This pattern of differential expression was confirmed by qRT-PCR. The expression of Lcn2 was decreased by low-protein diets when the diet contained soya oil, whereas the effect of protein was much smaller in the group fed diets prepared with corn oil. The decrease in Lcn2 expression produced by soya oil persisted into adult life. Levels of the Lcn2 protein were closely correlated to the mRNA abundance. The results suggest a possible involvement of Lcn2 in the programming of hepatic function.
\end{abstract}

Electronic supplementary material The online version of this article (doi:10.1007/s12263-013-0380-4) contains supplementary material, which is available to authorized users.

W. D. Rees $(\bowtie) \cdot$ S. M. Hay

The Rowett Institute of Nutrition and Health, The University of Aberdeen, Greenburn Road, Bucksburn, Aberdeen AB21 9SB, Scotland, UK

e-mail: w.rees@abdn.ac.uk
Keywords Programming - Hepatic development . Metabolism $\cdot$ Fetal origins of disease

$\begin{array}{ll}\text { Abbreviations } \\ \text { AA } & \text { Arachidonic acid } \\ \text { Acc1 } & \text { Acyl CoA carboxylase } \\ \text { DHA } & \text { Docosahexaenoic acid } \\ \text { L-CPT-1 } & \begin{array}{l}\text { Liver-type carnitine palmitoyltransferase } \\ \text { qRT-PCR }\end{array} \\ & \begin{array}{l}\text { Quantitative reverse transcriptase polymerase } \\ \text { chain reaction }\end{array}\end{array}$

\section{Introduction}

Despite a body of epidemiological evidence showing that a restricted maternal diet during gestation enhances the risks of metabolic disease in the offspring, molecular markers associated with the underlying mechanisms remain elusive (Gluckman et al. 2009; Tarry-Adkins and Ozanne 2011). The pregnant rat fed a low-protein diet is one of several wellestablished animal models in which poor fetal growth leads to adverse effects on blood pressure, glucose metabolism, and insulin action in adult life (Langley-Evans et al. 1996; Fernandez-Twinn et al. 2005; Rees et al. 2006; Warner and Ozanne 2010). Restricting the protein content of the maternal diet causes a wide range of physiological changes in both dam and fetus; however, many of these are homeostatic adaptations, with no long-lasting effects on the offspring, for example maintaining the amino acid supply in response to reduced protein intake. Nutrigenomic techniques (proteomics and transcriptomics) cannot differentiate between adaptive homeostatic responses and underlying programming mechanisms, limiting the value of these otherwise powerful tools. Fortunately, the nutritional basis of the low-protein model is 
more complicated. The final phenotype of the offspring is dependent not only on the protein content but also on other macronutrients in the maternal diet (Langley-Evans 2000). The fatty acid composition of the diet is a particularly important factor; diets prepared with soya oil have been shown to enhance the programming effect of protein deficiency compared to those prepared with corn oil. For example, the amount of insulin released in response to a glucose challenge is reduced in the offspring of dams fed protein-restricted diets prepared with soya oil (low in n-3 fatty acids), whereas when the maternal diet is prepared with corn oil (high in n-3 fatty acids), there is a minimal effect of protein deficiency, i.e., corn oil-based diets suppress the programming of postnatal glucose metabolism (Maloney et al. 2007). This interaction suggests that key pathways and molecules associated with the programming of insulin action should only be sensitive to the protein content of the maternal diet in the fetuses of dams fed the diets prepared with soya oil, whereas homeostatic changes associated with protein and amino acid metabolism should be present in both soya and corn oil groups.

The fetal liver is a key target for developmental programming with a central role in the metabolism of carbohydrates and fats (Desai et al. 1997; Maloney et al. 2003), and as with the glucose tolerance test, the programming of insulin action in the liver also depends on the fatty acid composition of the maternal diet. The levels of mRNAs coding for acyl CoA carboxylase-1 (Acc-1, a regulator of fatty acid synthesis) and liver-type carnitine acyl transferase-1 (L-CPT-1, a regulator of fatty acid beta-oxidation and transport) are higher following insulin stimulation in the offspring of dams fed the low-protein diet compared to those fed the high-protein diet prepared with soya oil; however, when the same diet is prepared with corn oil, the effect of protein restriction is much smaller (Maloney et al. 2007). To identify possible marker genes for developmental events in the liver, we have investigated differentially expressed mRNAs using microarray technology (transcriptomics). We reasoned that by comparing the patterns of gene expression in the fetal liver of rats fed diets with two levels of protein (18 vs. $9 \%$ ) prepared with corn (C) or soya oil (S) (C vs. S) in a $2 \times 2$ factorial design, we would be able to eliminate those mRNAs that responded to protein or oil alone. The remaining mRNAs that were either elevated or suppressed in the livers of the fetuses of dams fed low-protein diets prepared with soya oil compared to corn oil are likely to be of interest as both markers and possible components of the programming mechanism.

\section{Methods}

All experimental procedures were approved by the ethical review committee of the Rowett Research Institute and conducted in accordance with the UK Animals (Scientific Procedures) Act, 1986. Four groups of twelve female Rowett Hooded-Lister rats were randomly assigned to one of four experimental diets from approximately 8 weeks of age. The composition of the diets, containing $18 \% \mathrm{w} / \mathrm{w}$ (18) or $9 \%$ w/w casein (9) and $7 \%$ (w/w) of either C or S has been described previously (Maloney et al. 2007). After feeding the diets for approximately 2 weeks, the animals (body weight 200-250 g) were mated with normal males. The animals continued to be fed the experimental diets for the duration of gestation. On gestation day 21, dams were anesthetized, killed by cardiac puncture, and rapidly dissected. After the fetuses were killed, tissues were rapidly removed, frozen in liquid nitrogen, and stored at $-80{ }^{\circ} \mathrm{C}$ until required.

Microarray analysis of gene expression

Six dams were chosen from each treatment group, excluding those with large $(>12)$ or small $(<8)$ litters. Female fetuses were used as these were shown to be more affected in adult life (Maloney et al. 2007). The fetal liver from one female fetus was chosen randomly from each litter, and a portion was used for the preparation of total RNA with Trizol reagent (Sigma Poole Dorset UK) followed by DNase treatment as described previously (Maloney et al. 2005). All mRNA samples used had an RNA integrity number $>8$ (Agilent Bioanalyser), and sexing was verified by PCR. Samples of RNA were hybridized to Affymetrix Rat Genome 2302.0 microarrays (Affymetrix, Santa Clara CA. USA, provided through the NuGO array pipeline) by ServiceXS (Leiden NL) using their standard protocol.

\section{qRT-PCR}

Samples of $200 \mathrm{ng}$ total RNA were reverse transcribed using the TaqMan Reverse Transcription Reagents Kit (Applied Biosystems, Warrington, Cheshire, UK) primed with random hexamers. Primer and probe sets for lipocalin2 (Lcn2) were supplied by Applied Biosystems (Cat No: Rn00590612_ml) or as described previously (McNeil et al. 2008). The levels of cDNA were measured relative to the $18 \mathrm{~S}$ ribosomal RNA, and relative target quantity was calculated from the standard curve.

\section{Western blotting}

Samples of fetal liver were homogenized in 10 volumes of buffer $(150 \mathrm{mM} \mathrm{NaCl}, 1 \% \mathrm{NP}-40,0.5 \%$ sodium deoxycholate, $0.1 \%$ SDS, $10.8 \mathrm{mM}$ sodium phosphate $\mathrm{pH} 7.4$, $0.1 \mathrm{mM}$ PMSF, $5 \mathrm{mg} / \mathrm{ml}$ aprotinin). After centrifugation at $10,000 \times g$ for $15 \mathrm{~min}$ at $4{ }^{\circ} \mathrm{C}, 100 \mu \mathrm{g}$ of protein from the supernatant was separated on $15 \%$ SDS-PAGE. The gels 
were blotted to Immobilon-P membranes (Millipore, Watford, Herts., UK) Antibodies were obtained from R\&D Systems (Abingdon, Oxfordshire, UK), and conditions for Western blotting were as recommended by the manufacturer. The primary antibody (lipocalin-2/NGAL, Cat No: AF3508) was reconstituted as per the manufacture's instructions and used at 1:200 dilution $(1 \mu \mathrm{g} / \mathrm{ml})$. The secondary antibody (Anti-goat IgG-HRP, Cat No: HAF019) was used at 1:1,000 as per the manufacturer's instructions. The blots were visualized by ECL (Immobilon Western Chemiluminescent HRP substrate Cat No WBKLSO500, Millipore, Watford UK) and imaged with a Fuji Imager LAS3000. Blots were subsequently stripped and reprobed with anti-beta-actin (A5441, Sigma Poole Dorset UK, used at a dilution of 1:10,000 and anti-mouse IgG-HRP, Sigma Cat No A9044, used at a dilution of $1: 10,000)$.

\section{Statistical analysis}

The data generated by the microarrays were analyzed using the MadMax suite of programs (https://madmax.bioinfor matics.nl). All of the data met the appropriate quality control criteria and were normalized using the GCRMA (slow) program. Relative changes in mRNA levels were determined using linear models for microarray data, (LIMMA) module of GenePattern (Reich et al. 2006). The corrected gene expression data were analyzed by two-way ANOVA using Genstat (12th/13th edition, VSN International Ltd, Hemel Hempstead, UK). qRT-PCR and Western blot data were analyzed by ANOVA or REML as appropriate.

\section{Results}

Maternal live weight gain was reduced in animals fed the protein-restricted diet $(P<0.05)$, and the effect was greater in corn compared to soya oil diets (interaction protein.oil $P<0.05$ ) as shown in Table 1 . The protein and oil in the diet did not affect litter size. Fetal growth was reduced by protein restriction $(P<0.05)$, but it was unaffected by the oil type. Protein-restricted diets reduced the weight of the fetal liver by approximately $8 \%$, making the reduction in fetal growth comparable to the previous studies (Rees et al. 1999).

Following normalization, a total of $11,426 \mathrm{mRNAs}$ were found to be expressed above the background level in the fetal liver. In the first instance, we compared the patterns of mRNA abundance in the $18 \mathrm{~S}$ and $9 \mathrm{~S}$ groups, as this diet composition produced the greatest difference in hepatic gene expression in adult life (Maloney et al. 2007) and found a total of 110 mRNAs that were different
$(P<0.025)$. These candidate mRNAs were then analyzed by two-way ANOVA using the full dataset of soya and corn oil groups, testing for the effects of protein (Pr), oil (O), and their interactions (Pr.O). This analysis identified $40 \mathrm{mRNAs}$, the abundance of $6 \mathrm{mRNAs}$ altered by both protein and oil ( $\mathrm{Pr}$ and $\mathrm{O}, P<0.05$ ), and 34 where there was evidence for an interaction between the protein and oil content of the maternal diet (Pr.O, $P<0.05$ ). The remaining mRNAs were either not different or only influenced by the protein content $(n=9 \mathrm{Pr}, P<0.05$; O, $P>0.05)$ or oil in the maternal diet $(n=3 \operatorname{Pr}, P>0.05$; $\mathrm{O}, P<0.05)$. The ratio of abundance of the mRNAs that differed in the $18 \mathrm{~S}: 9 \mathrm{~S}$ groups ranged from $4.2: 1$ to $0.7: 1$ with 25 of these mRNAs downregulated by the $9 \%$ protein diet. Of these mRNAs, only 12 were increased by more than 1.25 -fold or reduced by 0.75 -fold by protein restriction as shown in Supplementary Table 1. For comparison, a similar analysis starting with a comparison of the $18 \mathrm{C}$ and 9C groups is shown in Supplementary Table 2. This analysis identified 17 mRNAs increased by more than 1.25fold or reduced by 0.75 -fold by protein restriction.

The mRNA identified as Lcn2 showed the largest change (4.2-fold) in response to protein restriction in the fetuses of the dams fed the diet containing soya oil, with little change in the fetuses of dams fed the corn oil diet ( $\mathrm{Pr}, P=0.045 ; \mathrm{O}$, $P=0.005 ; \mathrm{Pr} \cdot \mathrm{O}=$ n.s. $)$, a pattern of expression that closely matched the postnatal phenotype. Since the Lcn 2 mRNA was expressed at a high level, it was chosen for further study. Its expression was assessed by qRT-PCR using the mRNA samples used in the initial analysis. Expression was significantly different $(P<0.05)$ and showed a correlation between the abundance as determined by qRT-PCR and microarray analysis (linear regression $P<0.05, R^{2}>0.25$ ). As an additional confirmation, the expression of Lcn 2 was also examined in mRNA extracted from the liver of sibling fetuses and the combined data are shown in Fig. 1a. The Lcn 2 mRNA abundance is lower in the group fed $9 \%$ protein $(P=0.007)$ and also lower in the group where the maternal diet contains soya oil $(P=0.008)$. The effects were additive with no significant interaction between them $(P=0.27)$. The abundance of the Lcn 2 mRNA in the livers of the male fetuses (Fig. 1b) showed a similar numerical pattern with respect to the maternal diet but was more variable than in the females, with the result that there were no significant differences. Lcn2 expression was also analyzed in samples of liver from 6-week-old female offspring from a previous experiment (Fig. 1c). The expression relative to the $18 \mathrm{~S}$ RNA was substantially lower than at the fetal stages, but the mRNA for Lcn2 was still detectable. Expression in the offspring of dams fed the maternal diet containing soya oil was less than in the offspring of dams fed the corn oil diet $(P=0.035)$; however, there was no residual effect of protein $(P=0.16)$. 
Table 1 Maternal and fetal characteristics at day 21 of gestation

\begin{tabular}{|c|c|c|c|c|c|c|c|c|c|c|c|}
\hline \multirow[t]{2}{*}{ Diet $(n)$} & \multicolumn{2}{|c|}{ 18S (8) } & \multicolumn{2}{|c|}{ 9S (10) } & \multicolumn{2}{|c|}{$18 \mathrm{C}(9)$} & \multicolumn{2}{|l|}{$9 \mathrm{C}(6)$} & \multicolumn{3}{|c|}{$P$ value (two-way ANOVA) } \\
\hline & Mean & SEM & Mean & SEM & Mean & SEM & Mean & SEM & Protein & Oil & Protein $\times$ Oil \\
\hline Dam live Wt $(\mathrm{g})$ & 386 & 5 & 380 & 5 & 389 & 6 & 366 & 6 & 0.03 & ns & 0.05 \\
\hline Litter size & 15.9 & 0.9 & 14.9 & 0.7 & 14.0 & 0.7 & 14.3 & 1.3 & $\mathrm{~ns}$ & ns & ns \\
\hline Fetal wt $(\mathrm{g})^{\mathrm{a}}$ & 4.18 & 0.06 & 4.00 & 0.06 & 4.14 & 0.07 & 4.06 & 0.08 & 0.012 & ns & ns \\
\hline Fetal liver wt (mg) ${ }^{a}$ & 247.5 & 6.6 & 235.4 & 6.1 & 252.0 & 7.7 & 248.6 & 10.1 & 0.011 & ns & ns \\
\hline
\end{tabular}

Data are mean \pm SEM

${ }^{\text {a }}$ Female fetuses only and two-way ANOVA corrected for litter size as covariate (where $P<0.001$ ). ns $=P>0.05$

To confirm that the mRNA differentially expressed was full-length Lcn2, samples of cDNA were amplified using primers covering exons $1-5$ of the full-length Lcn2 mRNA. This produced a product of the anticipated size and sequence (not shown). Western blotting with an antibody against Lcn2 detected a single band of $25 \mathrm{kDa}$ (Fig. 2). Lcn2 expression is a part of the innate response to infection (Zhang et al. 2008), and a band of similar size was present in a sample of liver from an adult rat (Sal) infected with Salmonella enterica, which was included as a positive control. Analysis of the band density in fetal liver samples by two-way ANOVA showed expression was reduced in the soya oil group $(P<0.05)$ and tended $(P=0.069)$ to be reduced in the group fed the $9 \%$ protein diets. There was a linear correlation $\left(P<0.001, R^{2}=0.32\right)$ between the density of the spots on the Western blot and gene expression estimated by qRT-PCR. Immunocytochemistry of sections of fetal liver showed staining in discrete cells; however, this was not associated with specific anatomical features (data not shown).

\section{Discussion}

Numerous studies have made use of transcriptomics to evaluate complex phenotypes programed by nutritional insults and in many cases have identified genes associated with cell proliferation (Mortensen et al. 2010; Swali et al. 2011; Oster et al. 2012; Vijaya et al. 2013) and signaling pathways such as IGF-1 and progesterone (McNeil et al. 2009), a pattern consistent with the known function of these pathways in response to a restricted protein intake. However, it is clear that the programing by protein restriction is not simply a product of limited growth, which in the case of the fetal liver is equally affected by proteinrestricted diets prepared with either corn or soya oils. Despite a restriction in hepatic growth, the adult offspring of dams fed a corn oil-based diet exhibit very little programming of insulin action, differences are only apparent in the offspring of dams fed diets prepared with soya oil
(Maloney et al. 2007). This study has employed this observation to differentiate between these non-specific growth effects and identify potential gene markers associated with the programming mechanism(s). Maternal protein deficiency alters the abundance of slightly less than one hundred and fifty of the more than eleven thousand mRNAs present in the developing fetal liver irrespective of the maternal diet containing corn or soya oils. Interestingly, these mRNAs show markedly different patterns with very few common hits in soya versus corn. Unfortunately, the small number of targets limited the power of gene ontology analysis.

The mRNA with an abundance that most closely matched the postnatal phenotype was identified as Lcn2, also known as neutrophil gelatinase-associated lipocalin, siderocalin, and $24 \mathrm{p} 3$. The expression of the mRNA correlated closely with the abundance of the corresponding protein and was reduced when the dam was fed a low-protein diet, but crucially decreased further when the diet contained n-3 fatty acids from soya oil as opposed to n-6 from corn oil. This pattern of a substantial decrease in the expression of Lcn 2 in $9 \mathrm{~S}$ compared to $18 \mathrm{~S}$, and a much smaller change when comparing $9 \mathrm{C}$ to $18 \mathrm{C}$, closely resembles the pattern of programming of both glucose tolerance and hepatic gene expression in the offspring at 6 months of age (Maloney et al. 2007). Furthermore, the change in hepatic Lcn2 expression associated with exposure to the soya oil diet in utero persists into adult life. This close correlation strongly suggests that Lcn 2 may be part of the mechanism associated with the programming of hepatic glucose metabolism and gene expression.

Lipocalin-2 is a $24 \mathrm{kDa}$ secreted glycoprotein expressed in a variety of tissues. It has been shown to have a role in the sequestration of iron and is an important acute phase protein (Zhang et al. 2008). Lipocalin proteins bind a range of hydrophobic molecules including fatty acids, retinoids, and steroids (Akerstrom et al. 2000; Logdberg and Wester 2000; Wang 2012; Chakraborty et al. 2012). Although the endogenous ligand of Lcn 2 has yet to be identified, there is evidence that it may be involved in the metabolism of fatty 

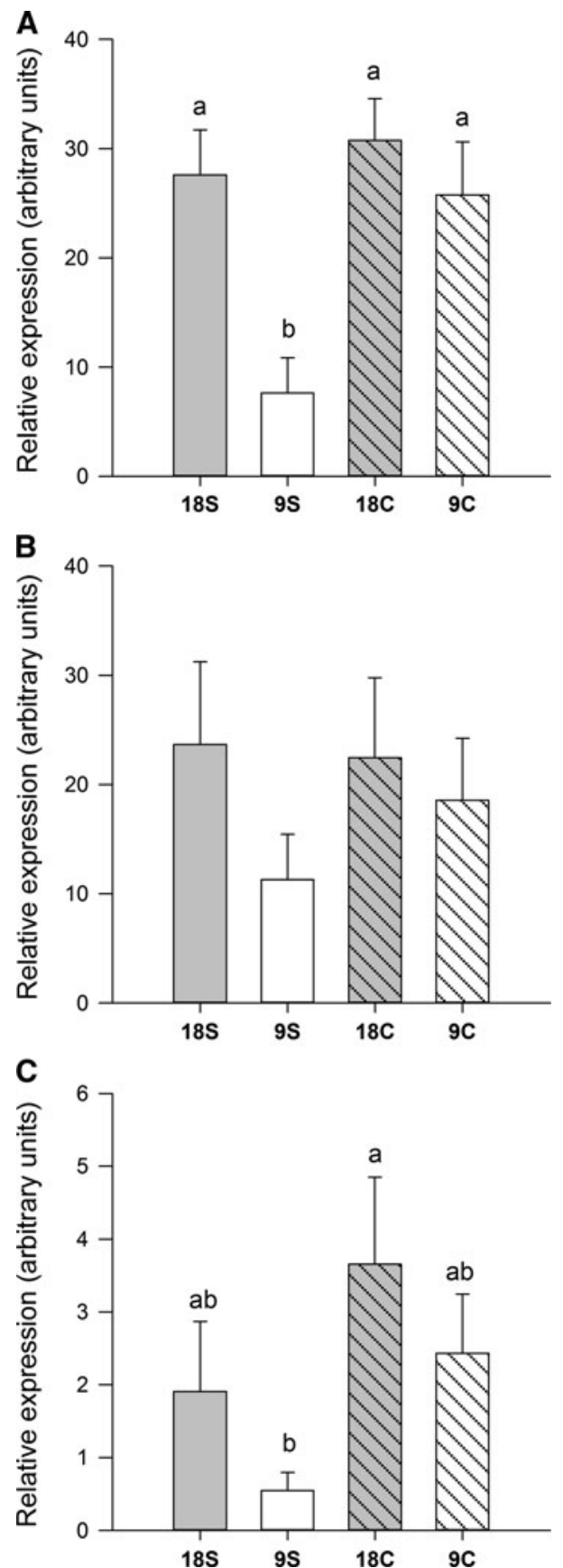

Fig. 1 Expression of lipocalin-2 (Lcn2) determined by qRT-PCR. Expression is relative to the $18 \mathrm{~S}$ ribosomal RNA in arbitrary units. Data are mean \pm SEM. Columns sharing a superscript letter are not significantly different $(P>0.05)$. a Expression in fetal liver of female fetuses on d 21 of gestation $18 \mathrm{~S} n=8,9 \mathrm{~S} n=10,18 \mathrm{C} n=8,9 \mathrm{C} n=7$. Data were analyzed by REML Protein $P=0.007$ Oil $P=0.008$ Protein $\cdot$ Oil $P=0.273$. b Expression in fetal liver of male fetuses on $\mathrm{d} 21$ of gestation ( $n=6$ for all groups). c Expression in liver of female offspring at 6 weeks of age ( $n=6$ for all groups). Data were analyzed by two-way ANOVA Protein $P=0.167$, Oil $P=0.035$, Protein $\cdot$ Oil $P=0.94$

acids (Law et al. 2010) and may play a role in remodeling the plasma membrane by redistributing polyunsaturated fatty acids among different types of phospholipids (Yang et al. 2012). Fatty acid analysis (McNeil and Rees unpublished) showed that n-3 fatty acids were lower (with DHA reduced by approximately $65 \%$ ) in animals fed the corn oil compared to the soya oil diets, and that there was also a corresponding small but significant $(P<0.05)$ increase in arachidonic acid (AA). Protein deficiency had no major effect on the abundance of DHA or AA. These differences in the ratios of $n-3$ and $n-6$ polyunsaturated fatty acids could be an important driver of changes in Lcn2. The promoter region of the Lcn 2 gene contains multiple transcription factor binding sites, which include glucocorticoid (Garay-Rojas et al. 1996) and estrogen response elements (Seth et al. 2002), suggesting that endocrine factors may also play a role in regulating Lcn2 expression. A number of studies have shown that exposure to excessive concentrations of glucocorticoids during fetal development programs hyperglycemia in the offspring (Drake et al. 2007); however, there was no correlation between corticosterone concentrations in fetal plasma and Lcn2 expression (McNeil and Rees unpublished data). Gender is also an important factor as the maternal diet programs hepatic lipid metabolism in female offspring, whereas in males, parameters like blood pressure are more sensitive. As Lcn 2 has been shown to modify estradiol production and estrogen receptor expression in metabolic tissues (Guo et al. 2012), gender-specific effects of a persistent change in its expression may become apparent later in life.

The Lcn2 mRNA is present in the liver, kidney, and spleen during organogenesis in the mouse (Garay-Rojas et al. 1996); however, animals lacking the Lcn2 gene develop normally with no apparent defects (Berger et al. 2006). In rodents, elevated serum Lcn 2 concentrations are a characteristic of several models of obesity (Yan et al. 2007), and mice with a targeted deletion of the Lcn 2 gene have disturbances in glucose and lipid metabolism when they are fed high-fat diets (Guo et al. 2010). In vitro, Lcn2 regulates apoptosis, growth, and development in a variety of cell types (Devireddy et al. 2005), suggesting that it has a secondary role in development. Such small non-critical changes in the structure and organization of organs and tissues are ideally suited to the regulation of metabolic plasticity. In this study, we have concentrated on the latter stages of hepatic development in the rat as this has been shown to be a critical period for the programming of insulin action in the low-protein model (Langley-Evans et al. 1996; Martin-Gronert and Ozanne 2010). Just before birth, there is a rapid increase in the weight of the fetal liver, which appears to be very sensitive to the maternal diet (Rees et al. 1999; Gruppuso et al. 2005). This suggests a possible involvement of Lcn2 in the changes in hepatic function, which take place around the time of birth and are associated with the acquisition of a more mature hepatocyte function. Lcn2 
Fig. 2 Lipocalin-2 protein levels in protein extracted from the liver of female fetuses at d21 of gestation. a The pixel density of replicate $100 \mu \mathrm{g}$ samples \pm SEM $(n=6)$. Data were analyzed by one-way ANOVA $P=0.017$, and columns sharing a superscript letter are not significantly different $(P>0.05)$. A typical blot is shown in the lower panel Sal $=25 \mu \mathrm{g}$ protein extracted from the liver of an adult rat infected with Salmonella enterica (Robertson et al. 2003). b Correlation between Lcn2 protein expression (pixel density on Western blots) and mRNA (relative expression by RT-PCR) of a subset of samples, $n=6$ per treatment. Line fitted by linear regression $\left(P<0.001, R^{2}=0.32\right)$
A
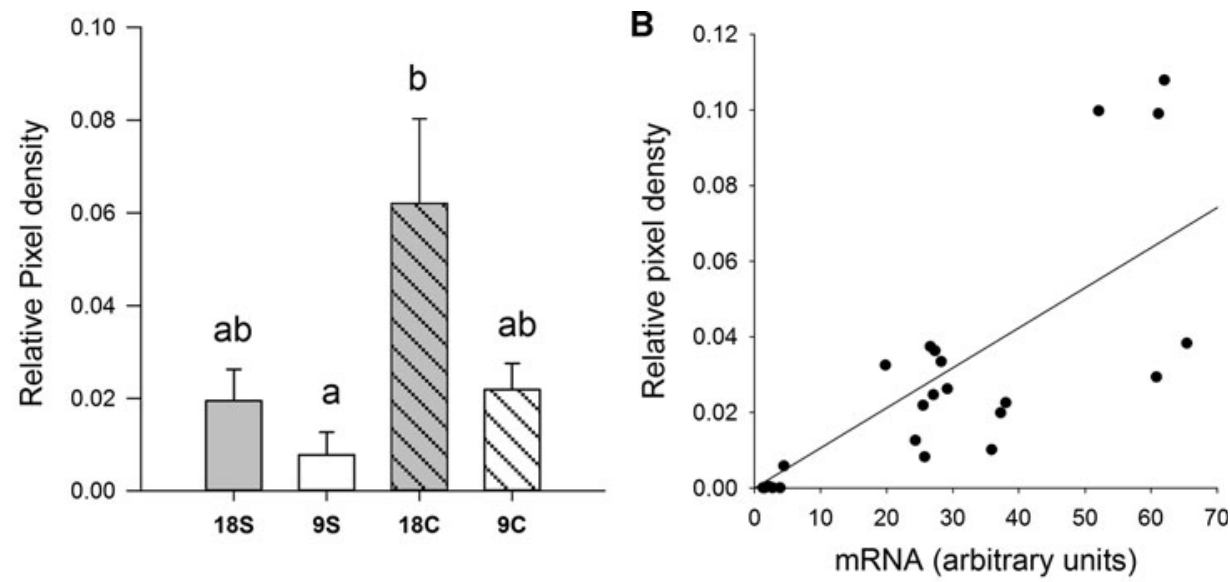
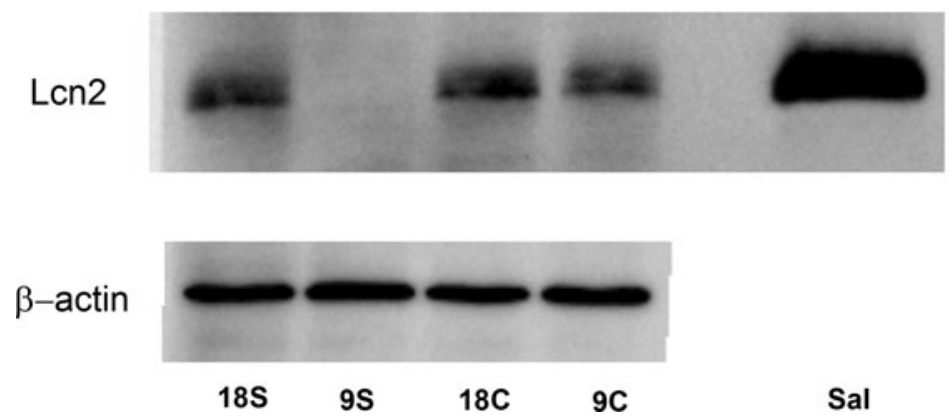

Sal has been shown to be a regulator of apoptosis in the hematopoietic compartment (Liu et al. 2011b), and the surge in Lcn2 expression may be associated with the transfer of hematopoietic cells from the liver to the bone marrow late in gestation.

In adult humans, elevated plasma concentrations of the homologous protein LCN2 have been reported in obese and insulin-resistant individuals, although these findings have not been replicated in all populations (Catalan et al. 2009; Wang et al. 2007; Wallenius et al. 2011; Liu et al. 2011a). It is interesting that LCN2 concentrations were increased in the plasma of pregnant women, with a high body mass index and furthermore were correlated with markers of insulin resistance (Cesur et al. 2012). Serum LCN2 was also higher in women with gestational diabetes and preeclampsia (D'Anna et al. 2008, 2009). These findings suggest that LCN2 may also be of value as a possible marker for fetal programming in humans.

Acknowledgments This work was supported by the Scottish Government Rural and Environment Research and Analysis Directorate (RERAD) as part of the core funding to the Rowett Research Institute and by the European Union sixth Framework programme EARNEST (CT-2005-007036). Affymetrix arrays were obtained through the NuGO array pipeline (European Union sixth Framework programme FP6-506360). We would like to thank Dr Claus-Dieter Mayer (Biomathematics and Statistics, Scotland) for his help with the analysis of the microarray data.

\section{References}

Akerstrom B, Flower, Salier JP (2000) Lipocalins: unity in diversity. Biochim Biophys Acta (BBA)—protein struct mol enzymol 1482:1-8

Berger T, Togawa A, Duncan GS, Elia AJ, You-Ten A, Wakeham A, Fong HEH, Cheung CC, Mak TW (2006) Lipocalin 2-deficient mice exhibit increased sensitivity to Escherichia coli infection but not to ischemia-reperfusion injury. Proc Natl Acad Sci USA 103:1834-1839

Catalan V, Gomez-Ambrosi J, Rodriguez A, Ramirez B, Silva C, Rotellar F, Gil MJ, Cienfuegos JA, Salvador J, Fruhbeck G (2009) Increased adipose tissue expression of lipocalin-2 in obesity is related to inflammation and matrix metalloproteinase2 and metalloproteinase- 9 activities in humans. J Mol Med (Berl) 87:803-813

Cesur S, Yucel A, Noyan V, Sagasoz N (2012) Plasma lipocalin-2 levels in pregnancy. Acta Obstet Gynecol Scand 91:112-116

Chakraborty S, Kaur S, Guha S, Batra SK (2012) The multifaceted roles of neutrophil gelatinase associated lipocalin (NGAL) in inflammation and cancer. Biochim Biophys Acta (BBA)-Rev Cancer 1826:129-169

D’Anna R, Baviera G, Giordano D, Todarello G, Corrado F, Buemi M (2008) Second trimester neutrophil gelatinase-associated lipocalin as a potential prediagnostic marker of preeclampsia. Acta Obstet Gynecol Scand 87:1370-1373

D’Anna R, Baviera G, Corrado F, Giordano D, Recupero S, Di BA (2009) First trimester serum neutrophil gelatinase-associated lipocalin in gestational diabetes. Diabet Med 26:1293-1295

Desai M, Byrne CD, Meeran K, Martenz ND, Bloom SR, Hales CN (1997) Regulation of hepatic enzymes and insulin levels in offspring of rat dams fed a reduced-protein diet. Am J Physiol 273:G899-G904 
Devireddy LR, Gazin C, Zhu X, Green MR (2005) A cell-surface receptor for lipocalin $24 \mathrm{p} 3$ selectively mediates apoptosis and iron uptake. Cell 123:1293-1305

Drake AJ, Tang JI, Nyirenda MJ (2007) Mechanisms underlying the role of glucocorticoids in the early life programming of adult disease. Clin Sci 113:219-232

Fernandez-Twinn DS, Wayman A, Ekizoglou S, Martin MS, Hales CN, Ozanne SE (2005) Maternal protein restriction leads to hyperinsulinemia and reduced insulin-signaling protein expression in 21-mo-old female rat offspring. Am J Physiol Regul Integr Comp Physiol 288:R368-R373

Garay-Rojas E, Harper M, Hraba-Renevey S, Kress M (1996) An apparent autocrine mechanism amplifies the dexamethasone- and retinoic acid-induced expression of mouse lipocalin-encoding gene 24p3. Gene 170:173-180

Gluckman PD, Hanson MA, Buklijas T, Low FM, Beedle AS (2009) Epigenetic mechanisms that underpin metabolic and cardiovascular diseases. Nat Rev Endocrinol 5:401-408

Gruppuso PA, Boylan JM, Anand P, Bienieki TC (2005) Effects of maternal starvation on hepatocyte proliferation in the late gestation fetal rat. Pediatr Res 57:185-191

Guo H, Jin D, Zhang Y, Wright W, Bazuine M, Brockman DA, Bernlohr DA, Chen X (2010) Lipocalin 2 deficiency impairs thermogenesis and potentiates diet-induced insulin resistance in mice. Diabetes 59:1376-1385

Guo H, Zhang Y, Brockman DA, Hahn W, Bernlohr DA, Chen X (2012) Lipocalin 2 deficiency alters estradiol production and estrogen receptor signaling in female mice. Endocrinology 153:1183-1193

Langley-Evans SC (2000) Critical differences between two low protein diet protocols in the programming of hypertension in the rat. Int J Food Sci Nutr 51:11-17

Langley-Evans SC, Gardner DS, Jackson AA (1996) Association of disproportionate growth of fetal rats in late gestation with raised systolic blood pressure in later life. J Reprod Fertil 106:307-312

Law IKM, Xu A, Lam KSL et al (2010) Lipocalin-2 deficiency attenuates insulin resistance associated with aging and obesity. Diabetes 59:872-882

Liu X, Hamnvik OP, Petrou M, Gong H, Chamberland JP, Christophi CA, Kales SN, Christiani DC, Mantzoros CS (2011a) Circulating lipocalin-2 is associated with body fat distribution at baseline, but is not an independent predictor of insulin resistance: the prospective cyprus metabolism study. Eur $\mathrm{J}$ Endocrinol 165:805-812

Liu Z, Yang A, Wang Z, Bunting KD, Davuluri G, Green MR, Devireddy LR (2011b) Multiple apoptotic defects in hematopoietic cells from mice lacking lipocalin 24p3. J Biol Chem 286:20606-20614

Logdberg L, Wester L (2000) Immunocalins: a lipocalin subfamily that modulates immune and inflammatory responses. Biochim Biophys Acta 1482:284-297

Maloney CA, Gosby AK, Phuyal JL, Denyer GS, Bryson JM, Caterson ID (2003) Site-specific changes in the expression of fatpartitioning genes in weanling rats exposed to a low-protein diet in utero. Obes Res 11:461-468

Maloney CA, Lilley C, Cruickshank M, McKinnon C, Hay SM, Rees WD (2005) The expression of growth-arrest genes in the liver and kidney of the protein-restricted rat fetus. Br J Nutr 94:12-18

Maloney CA, Lilley C, Czopek A, Hay SM, Rees WD (2007) Interactions between protein and vegetable oils in the maternal diet determine the programming of the insulin axis in the rat. $\mathrm{Br}$ J Nutr 97:912-920

Martin-Gronert MS, Ozanne SE (2010) Mechanisms linking suboptimal early nutrition and increased risk of type 2 diabetes and obesity. J Nutr 140:662-666

McNeil CJ, Hay SM, Rucklidge G, Reid M, Duncan G, Maloney CA, Rees WD (2008) Disruption of lipid metabolism in the liver of the pregnant rat fed folate deficient and methyl donor deficient diets. Br J Nutr 99:262-271

McNeil CJ, Hay SM, Rucklidge GJ, Reid MD, Duncan GJ, Rees WD (2009) Gene and protein expression profiles in the foetal liver of the pregnant rat fed a low protein diet. Genes Nutr 4:189-194

Mortensen OH, Olsen HL, Frandsen L, Nielsen PE, Nielsen FC, Grunnet N, Quistorff B (2010) Gestational protein restriction in mice has pronounced effects on gene expression in newborn offspring's liver and skeletal muscle; protective effect of taurine. Pediatr Res 67:47-53

Oster M, Murani E, Metges CC, Ponsuksili S, Wimmers K (2012) A low protein diet during pregnancy provokes a lasting shift of hepatic expression of genes related to cell cycle throughout ontogenesis in a porcine model. BMC Genom 13:93

Rees WD, Hay SM, Buchan V, Antipatis C, Palmer RM (1999) The effects of maternal protein restriction on the growth of the rat fetus and its amino acid supply. Br J Nutr 81:243-250

Rees WD, Hay SM, Cruickshank M, Reusens B, Remacle C, Antipatis C, Grant G (2006) Maternal protein intake in the pregnant rat programs the insulin axis and body composition in the offspring. Metabolism 55:642-649

Reich M, Liefeld T, Gould J, Lerner J, Tamayo P, Mesirov JP (2006) GenePattern 2.0. Nat Genet 38:500-501

Robertson JMC, McKenzie NH, Duncan M, len-Vercoe E, Woodward MJ, Flint HJ, Grant G (2003) Lack of flagella disadvantages Salmonella enterica serovar Enteritidis during the early stages of infection in the rat. J Med Microbiol 52:91-99

Seth P, Porter D, Lahti-Domenici J, Geng Y, Richardson A, Polyak K (2002) Cellular and molecular targets of estrogen in normal human breast tissue. Cancer Res 62:4540-4544

Swali A, McMullen S, Hayes H, Gambling L, McArdle HJ, LangleyEvans SC (2011) Cell cycle regulation and cytoskeletal remodelling are critical processes in the nutritional programming of embryonic development. PLoS ONE 6:e23189

Tarry-Adkins JL, Ozanne SE (2011) Mechanisms of early life programming: current knowledge and future directions. Am J Clin Nutr 94:1765S-1771S

Vijaya M, Manikandan J, Parakalan R, Dheen ST, Kumar SD, Tay SSW (2013) Differential gene expression profiles during embryonic heart development in diabetic mice pregnancy. Gene 516:218-227

Wallenius V, Elias E, Bergstrom GM, Zetterberg H, Behre CJ (2011) The lipocalins retinol-binding protein-4, lipocalin-2 and lipocalin-type prostaglandin D2-synthase correlate with markers of inflammatory activity, alcohol intake and blood lipids, but not with insulin sensitivity in metabolically healthy 58-year-old Swedish men. Exp Clin Endocrinol Diabetes 119:75-80

Wang Y (2012) Small lipid-binding proteins in regulating endothelial and vascular functions: focusing on adipocyte fatty acid binding protein and lipocalin-2. Br J Pharmacol 165:603-621

Wang Y, Lam KSL, Kraegen EW et al (2007) Lipocalin-2 is an inflammatory marker closely associated with obesity, insulin resistance, and hyperglycemia in humans. Clin Chem 53:34-41

Warner MJ, Ozanne SE (2010) Mechanisms involved in the developmental programming of adulthood disease. Biochem $\mathbf{J}$ 427:333-347

Yan QW, Yang Q, Mody N, Graham TE, Hsu CH, Xu Z, Houstis NE, Kahn BB, Rosen ED (2007) The adipokine lipocalin 2 is regulated by obesity and promotes insulin resistance. Diabetes 56:2533-2540

Yang B, Fan P, Xu A et al (2012) Improved functional recovery to I/R injury in hearts from lipocalin-2 deficiency mice: restoration of mitochondrial function and phospholipids remodeling. Am J Transl Res 4:60-71

Zhang J, Wu Y, Zhang Y, LeRoith D, Bernlohr DA, Chen X (2008) The role of lipocalin 2 in the regulation of inflammation in adipocytes and macrophages. Mol Endocrinol 22:1416-1426 